\title{
Espacialização da erosividade mensal e anual da chuva na bacia hidrográfica do
}

\section{Córrego Fundo, Aquidauana-MS}

Spatialization of monthly and annual rainfall erosivity in the Córrego Fundlo hydrographic basin, Aquidauana-MS

Espacialización de la erosividad pluvial mensual y anual en la cuenca hidrográfica Córrego Fundo, Aquidauana-MS

Elyson Thiago de Souza Florentim

ORCID: https://orcid.org/0000-0002-9722-6713 Universidade Estadual de Mato Grosso do Sul, Brasil E-mail: thiagoflorentim28@gmail.com

Helen Caroline Rodrigues Correa

ORCID: https://orcid.org/0000-0002-9546-2886 Universidade Estadual de Mato Grosso do Sul, Brasil E-mail: helen.correa05@gmail.com

Felipe das Neves Monteiro

ORCID: https://orcid.org/0000-0002-8024-6953 Universidade Estadual de Mato Grosso do Sul, Brasil E-mail: felipeuems@gmail.com

Karina dos Santos Falcão

ORCID: https://orcid.org/0000-0001-6973-1723 Universidade Estadual de Mato Grosso do Sul, Brasil E-mail: falcao_karina@hotmail.com

Elói Panachuki

ORCID: https://orcid.org/0000-0002-5816-7466 Universidade Estadual de Mato Grosso do Sul, Brasil E-mail: eloip@uems.br

\begin{abstract}
Resumo
Objetivo do trabalho foi realizar a espacialização da erosividade mensal e anual da bacia hidrográfica do Córrego Fundo, Aquidauana-MS, por meio do uso de um Sistemas de Informações Geográficas. Para a caracterização da precipitação pluviométrica e da erosividade, foi considerado séries históricas de 28 anos, correspondente aos anos 1991-2019 de 5 estações meteorológicas pertencentes à rede hidrometeorológica da Agência Nacional e 1 estação da CEMTEC/MS no período de 2008-2018. A determinação da erosividade foi feita de acordo com a equação potencial ajustada para o município de Campo-Grande, MS e posteriormente espacializada para toda a bacia, por meio software ArcGis PRO 2.5.2. A erosividade média anual variou entre 7749,29 a 7800,55 $\mathrm{MJ} \mathrm{mm} \mathrm{ha}{ }^{-1} \mathrm{~h}^{-1}$ ano, com uma erosividade média de $7.781 \mathrm{MJ} \mathrm{mm} \mathrm{ha}{ }^{-1} \mathrm{~h}^{-1}$ ano. Os meses de maiores erosividade estão relacionados com os períodos chuvosos da região. Alguns meses do ano a erosividade mensal foi classificada muito baixo a baixo, no entanto a erosividade média anual foi considerado alta. Os resultados deste trabalho apresentam informações relevante para subsidiar o planejamento de conservação do solo e da água, pois foi possível verificar ao longo do ano os meses que apresenta maiores suscetibilidade a erosão.
\end{abstract}

Palavras-chave: Conservação do solo e da água; Erosão do solo; Sistemas de Informações Geográficas; RUSLE.

\begin{abstract}
Objective of the work was to perform the spatialization of the monthly and annual erosivity of the hydrographic basin of Córrego Fundo, Aquidauana-MS, through the use of a Geographic Information Systems. For the characterization of rainfall and erosivity, historical series of 28 years were considered, corresponding to the years 1991-2019 of 5 weather stations belonging to the hydrometeorological network of the National Agency and 1 station of CEMTEC / MS - in the period 2008-2018. The erosivity determination was made according to the potential equation adjusted for the municipality of Campo-Grande, MS and later spatialized for the entire basin, using ArcGis PRO 2.5.2 software. The average annual erosivity ranged from 7749.29 to $7800.55 \mathrm{MJ} \mathrm{mm} \mathrm{ha}^{-1} \mathrm{~h}^{-1}$ year, with an average erosivity of 7,781 MJ $\mathrm{mm} \mathrm{ha}{ }^{-1} \mathrm{~h}^{-1}$ year. The months of greatest erosivity are related to the rainy periods in the region. Some months of the year, monthly erosivity was rated very low to low, however the average annual erosivity was considered high. The results of this work present relevant information to support the planning of soil and water conservation, as it was possible to verify, throughout the year, the months that present the greatest susceptibility to erosion.
\end{abstract}


Keywords: Soil and water conservation; Soil erosion; Geographic Information Systems; RUSLE.

\section{Resumen}

El objetivo del trabajo fue realizar la espacialización de la erosividad mensual y anual de la cuenca hidrográfica de Córrego Fundo, Aquidauana-MS, mediante el uso de un Sistema de Información Geográfica. Para la caracterización de la precipitación y la erosividad se consideraron series históricas de 28 años, correspondientes a los años 1991-2019 de 5 estaciones meteorológicas pertenecientes a la red hidrometeorológica de la Agencia Nacional y 1 estación de CEMTEC / MS - en el período 2008-2018. La determinación de la erosividad se realizó de acuerdo con la ecuación de potencial ajustada para el municipio de Campo-Grande, MS y luego espacializada para toda la cuenca, utilizando el software ArcGis PRO 2.5.2. La erosividad media anual osciló entre 7749,29 y 7800,55 MJ mm ha-1 $\mathrm{h}^{-1}$ año, con una erosividad media de 7,781 $\mathrm{MJ} \mathrm{mm} \mathrm{ha}^{-1} \mathrm{~h}^{-1}$ año. Los meses de mayor erosividad están relacionados con los períodos lluviosos de la región. Algunos meses del año, la erosividad mensual se calificó de muy baja a baja, sin embargo, la erosividad anual promedio se consideró alta. Los resultados de este trabajo presentan información relevante para sustentar la planificación de la conservación de suelos y aguas, ya que se pudo verificar, a lo largo del año, los meses que presentan mayor susceptibilidad a la erosión.

Palabras clave: Conservación de suelos y aguas; La erosión del suelo; Sistemas de Información Geográfica; RUSLE.

\section{Introduçãa}

A erosão é um fenômeno natural, sendo uma das principais formas da degradação do solo, provoca grandes impactos na produtividade agrícola, qualidade da água, riscos ambientais e econômico em todo o mundo (Fayas et al., 2019). Os principais fatores que controlam a erosão do solo, são cobertura vegetal, erodibilidade, topografia e a erosividade, sendo este último fator o mais difícil de prever e controlar (Martinez \& Begueria, 2009).

As mudanças climáticas podem proporcionar alterações nas características da chuva, causar eventos intenso de precipitação, o que são responsáveis por grande parte de transporte de sedimentos, constituindo, assim, preocupação para a conservação do solo e de água (Oliveira et al., 2012), portanto estimar a erosividade da chuva é fundamental para avaliar os riscos de perdas de solo. A erosividade da chuva é um dos parâmetros de entrada mais importantes para descrever os processos erosivos e propor medidas de conservação do solo e da água por meio de modelos de previsão de erosão do solo. Visto que a erosão do solo é difícil de medir em grandes escalas, sendo assim necessários modelos para estimar a perda de solo por erosão hídrica em escalas regional, nacional e continental. As previsões em pequenas e grandes escala são de extrema importância, uma vez que a erosão, além da impermeabilização do solo, é a maior ameaça à sustentabilidade e consequentemente, à segurança hídrica e alimentar (Panagos et al., 2017).

O fator R, denominado erosividade da chuva, compõem a Equação Universal de Perdas de Solo, é um índice numérico representado pelo produto da energia cinética total da chuva (E), pela intensidade máxima em 30 min $\left(I_{30}\right)$, ou seja, pelo índice $\mathrm{EI}_{30}$, conforme consta Wishmeier \& Smith. (1978). O índice $\mathrm{EI}_{30}$ é o somatório de todas as chuvas individuais de um determinado mês, o que corresponde a erosividade mensal, enquanto o somatório dos valores mensais de doze meses representa $\mathrm{EI}_{30}$ anual. Ao utilizar a erosividade média anual das chuvas compreendidos por um período de 20 anos ou mais, é possível obter o fator $\mathrm{R}$ médio anual de determinado local (Bertoni \& Lombardi Neto, 1999), vários estudos consideram o EI 30 como o índice que melhor se ajusta à realidade das regiões tropicais (Silva et al., 2010; Bertoni \& Lombardi Neto, 1999; Arai et al., 2010).

A determinação dos valores da erosividade ao longo do ano, permite identificar os meses nos quais os riscos de perdas de solo e água são mais elevados, o que possibilita realizar o planejamento adequado do preparo do solo, período de plantio e colheita de acordo com as exigências de cada cultura. O estudo em microbacias hidrográficas como uma unidade de planejamento, monitoramento e avaliação do uso dos recursos naturais é o primeiro passo para projetos de conservação. O segundo passo é a organização de estratégias para promover a melhoria da produtividade agrícola e o uso de tecnologias adequadas sob o ponto de vista ambiental, econômico e social (Ministério da Agricultura, Pecuária e Abastecimento).

Neste sentido, a avaliação quantitativa da erosão potencial do solo causada pelas chuvas é importante para prever o risco de erosão do solo e melhorar o planejamento de conservação do solo e da água. Diante do exposto o objetivo do trabalho foi 
realizar a espacialização da erosividade média mensal e anual da micro bacia hidrográfica do Córrego Fundo, Aquidauana-MS, por meio do uso de Sistemas de Informações Geográficas.

\section{Metodologia}

A Bacia Hidrográfica do Córrego Fundo está localizada na região sudeste do município de Aquidauana no estado de Mato

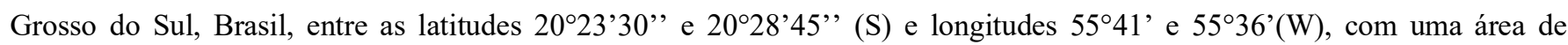
aproximadamente 4564,49 hectares. O Córrego Fundo é afluente do rio Aquidauana no qual é um dos principais afluentes da Bacia Hidrográfica do Paraguai, com influência direta no regime de cheias do Pantanal (Fig. 1).

Figura 1. Localização e delimitação da bacia hidrográfica do Córrego Fundo, Aquidauana - MS.

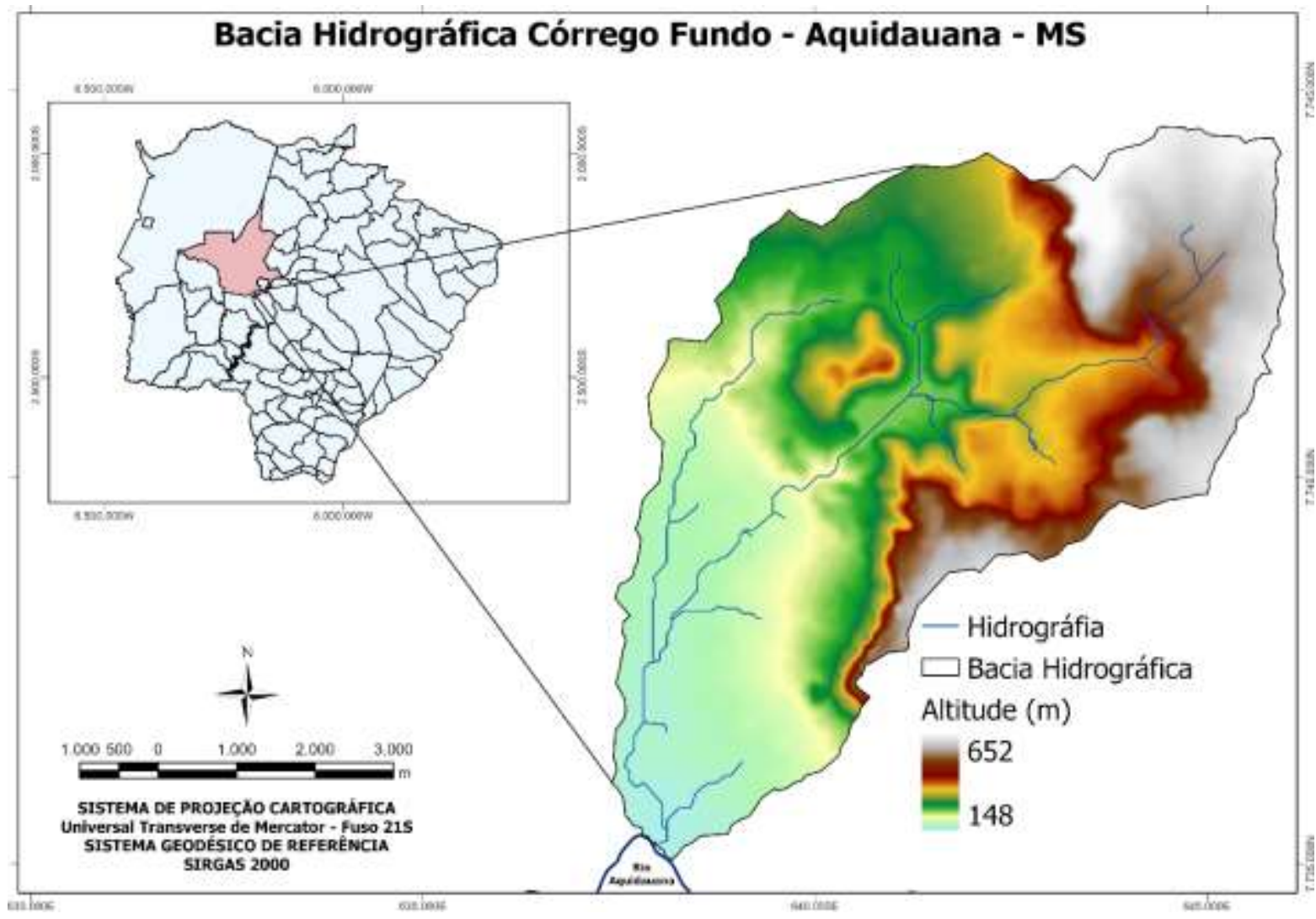

Fonte: Autores, (2020)

Para a caracterização da precipitação pluviométrica e da erosividade, foram utilizadas séries históricas de 28 anos, correspondente aos anos 1991-2019 de cinco estações meteorológicas, pertencentes à rede hidrometeorológica da Agência Nacional de Águas (ANA) e uma estação da CEMTEC/MS - SEMAGRO (Centro de Monitoramento do Tempo e do Clima de Mato Grosso do Sul - Secretaria de Estado de Meio Ambiente, Desenvolvimento Econômico, Produção e Agricultura Familiar) no período de 2008-2018 (Tabela 1). 
Tabela 1. Caracterização das estações pluviométricas selecionadas para estudo da erosividade na Bacia Hidrográfica do Córrego Fundo.

\begin{tabular}{llccc}
\hline Estação & Código & Lat & Long & Período \\
\hline Iguaçu & 1955000 & $-19,94$ & $-55,79$ & $1991-2019$ \\
Cipolândia & 2055001 & $-20,13$ & $-55,39$ & $1991-2019$ \\
Palmeira & 2055002 & $-20,45$ & $-55,43$ & $1991-2019$ \\
Faz. Lageado & 2055003 & $-20,29$ & $-55,45$ & $1991-2019$ \\
Taboco & 2055004 & $-20,07$ & $-55,65$ & $1991-2019$ \\
Aquidauana & Semagro & $-20,48$ & $-55,78$ & $2008-2019$ \\
\hline
\end{tabular}

Fonte: Autores, (2020)

Visando obter uma série histórica mensal e anual contínua, bem como um único banco de dados com valores representativos para a área de estudo, foi necessário a realização de estudos de consistência, homogeneidade e preenchimento de falhas entre as estações de acordo com Mello et al., (2018).

A determinação da erosividade, foi realizada de acordo com metodologia descrita por Oliveira et al. (2012), sendo utilizada a equação potencial ajustada para o município de Campo Grande, MS. O valor do fator R é resultante da soma dos valores mensais dos Índice de Erosão $\left(\mathrm{E}_{\mathrm{I} 30}\right)$ obtido por meio da equação 1, desenvolvida para o estado de Mato Grosso do Sul.

Em que:

$$
\mathrm{E}_{\mathrm{I} 30}=139,44(\mathrm{Pm} 2 / \mathrm{Pa})^{0,6784}
$$

$\mathrm{E}_{\mathrm{I} 30}=$ média mensal do índice de erosão, em $\mathrm{MJ} \mathrm{mm} \mathrm{ha}^{-1} \mathrm{~h}^{-1}$;

$\mathrm{Pm}=$ precipitação média mensal em milímetros;

$\mathrm{Pa}=$ precipitação média anual em milímetros.

A espacialização da erosividade média e mensal foi obtida por meio da interpolação IDW (Inverse Distance Weighted), utilizando o software ArcGis PRO 2.5.2, com o objetivo de gerar a imagem matricial da Erosividade mensal e média anual para a bacia hidrográfica do Córrego Fundo. O método de interpolação IDW parte do pressuposto que quanto mais próximo estiver um ponto do outro, maior será a correlação entre seus valores, assim este método permite representar uma maior distribuição espacial da erosividade (Anjos et al, 2016).

Os resultados de erosividade foram classificados de acordo com as classes da Tabela 2, adaptado por Santos (2008).

Tabela 2. Classe da erosividade das chuvas mensal e anual.

\begin{tabular}{|c|c|c|}
\hline \multirow{2}{*}{ Classe de erosividade } & \multicolumn{2}{|c|}{ Valores de erosividade } \\
\hline & MJ mm ha ${ }^{-1} h^{-1}$ ano $^{-1}$ & MJ mm ha ${ }^{-1} h^{-1}$ mês $^{-1}$ \\
\hline Muito Baixa & $\mathrm{R}<2500$ & $\mathrm{R}<250$ \\
\hline Baixa & $2500<\mathrm{R}<5000$ & $250<\mathrm{R}<500$ \\
\hline Média & $5000<\mathrm{R}<7000$ & $500<\mathrm{R}<700$ \\
\hline Alta & $7000<\mathrm{R}<10000$ & $700<\mathrm{R}<1000$ \\
\hline Muito Alta & $\mathrm{R}>10000$ & $\mathrm{R}>1000$ \\
\hline
\end{tabular}

Fonte: Santos, (2008). 


\section{Resultados e Discussões}

Na Figura 2, é apresentado a espacialização da precipitação média anual, do período de 1991 a 2019. Observa-se que a precipitação obteve pouca variação ao longo da bacia, com precipitação média de 1268,52 mm, semelhante aos resultados encontrados por Silva \& Bacani, (2017) realizado na mesma área de estudo.

Figura 2. Espacialização da precipitação anual para a bacia hidrográfica Córrego Fundo, Aquidauana -MS.

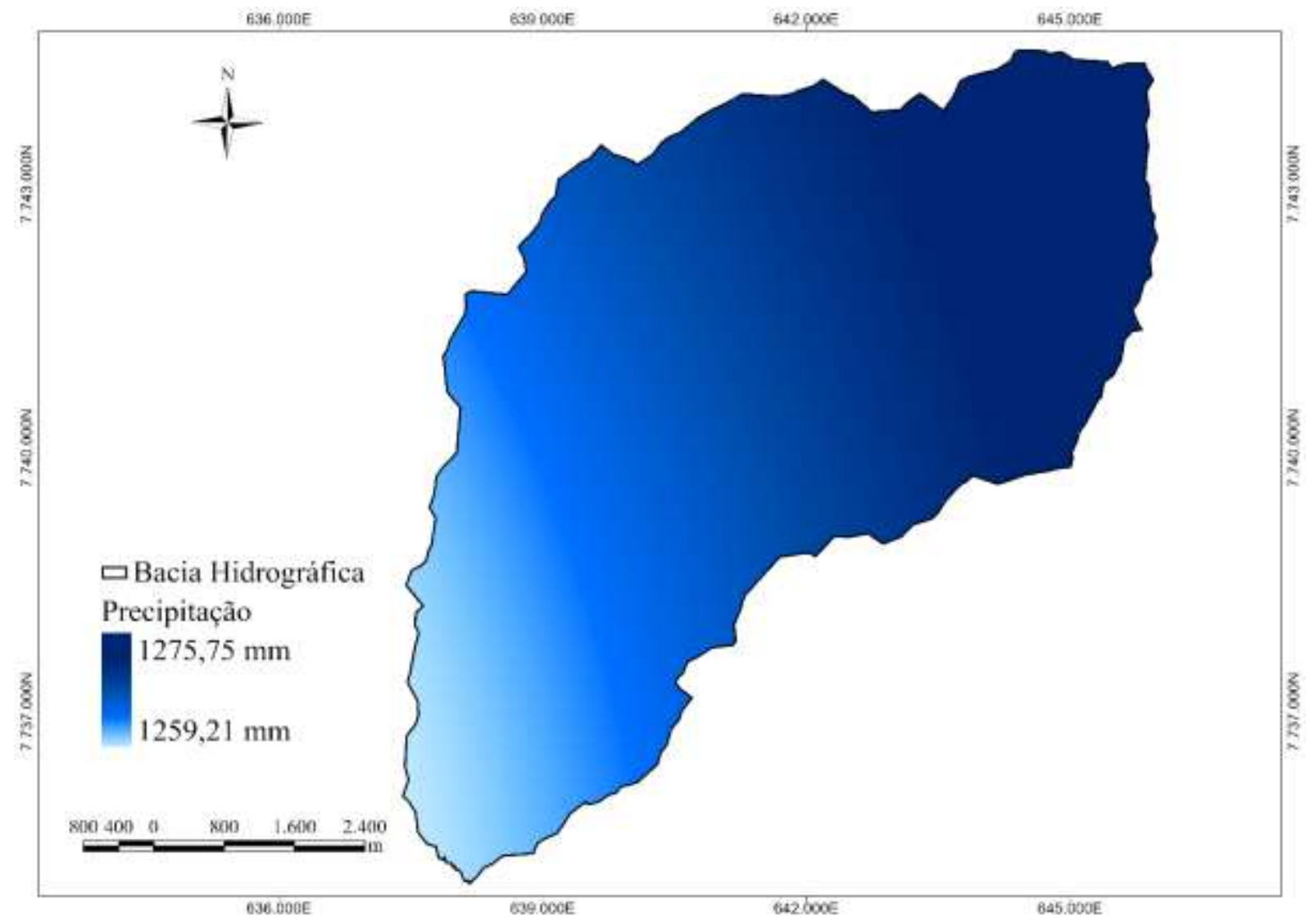

Fonte: Autores, (2020)

É apresentado a distribuição das chuvas ao longo do ano (Fig. 3). Esses resultados permitem determinar quais os meses acontece as maiores e menores precipitação, o que confere informações de grande relevância para um melhor planejamento. Ao longo dos meses é verificado variação da precipitação de 27,03 mm a 197,91 mm, em que nos meses de abril a setembro foram encontradas as menores precipitações, enquanto nos meses de outubro a março foi verificado as maiores chuvas, assim é possível definir ao longo do ano os períodos secos e chuvosos. 
Figura 3. Espacialização da precipitação mensal (mm), para a bacia hidrográfica do Córrego Fundo, Aquidauana -MS.

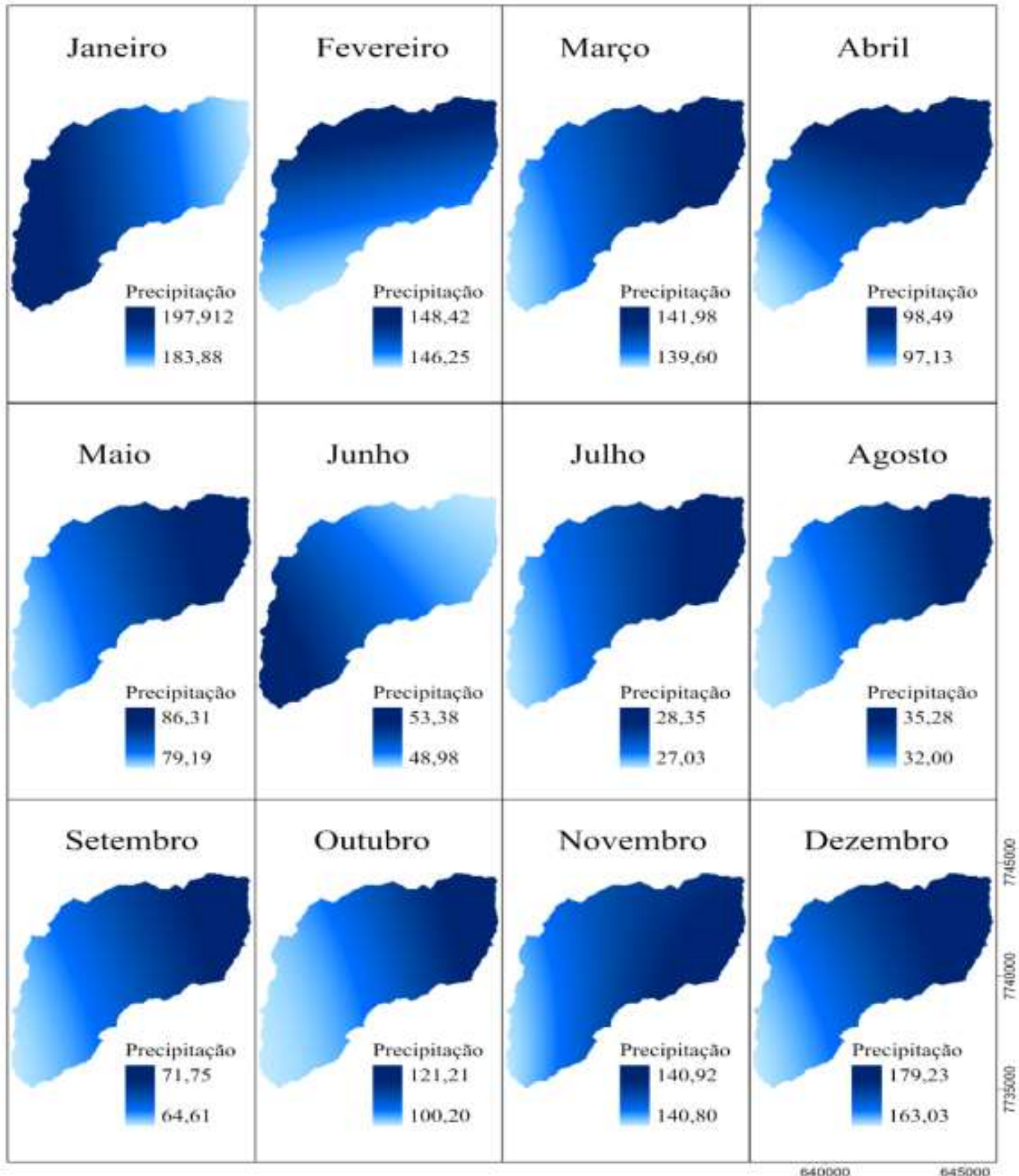

Fonte: Autores, (2020)

Na Figura 4, está representada a distribuição da erosividade média anual. Os valores encontram-se entre 7749,29 a 7800,55 MJ mm ha $\mathrm{M} \mathrm{h}^{-1}$ ano, com pouca variação dentro da bacia, seguindo a mesma tendencia da precipitação. De acordo com a Tabela 2, os resultados obtidos são classificados como erosividade alta em toda área de estudo. 
Figura 4. Espacialização da erosividade anual (MJ mm ha-1 $\mathrm{h}^{-1}$ ano) das chuvas na bacia hidrográfica Córrego Fundo, Aquidauana - MS.

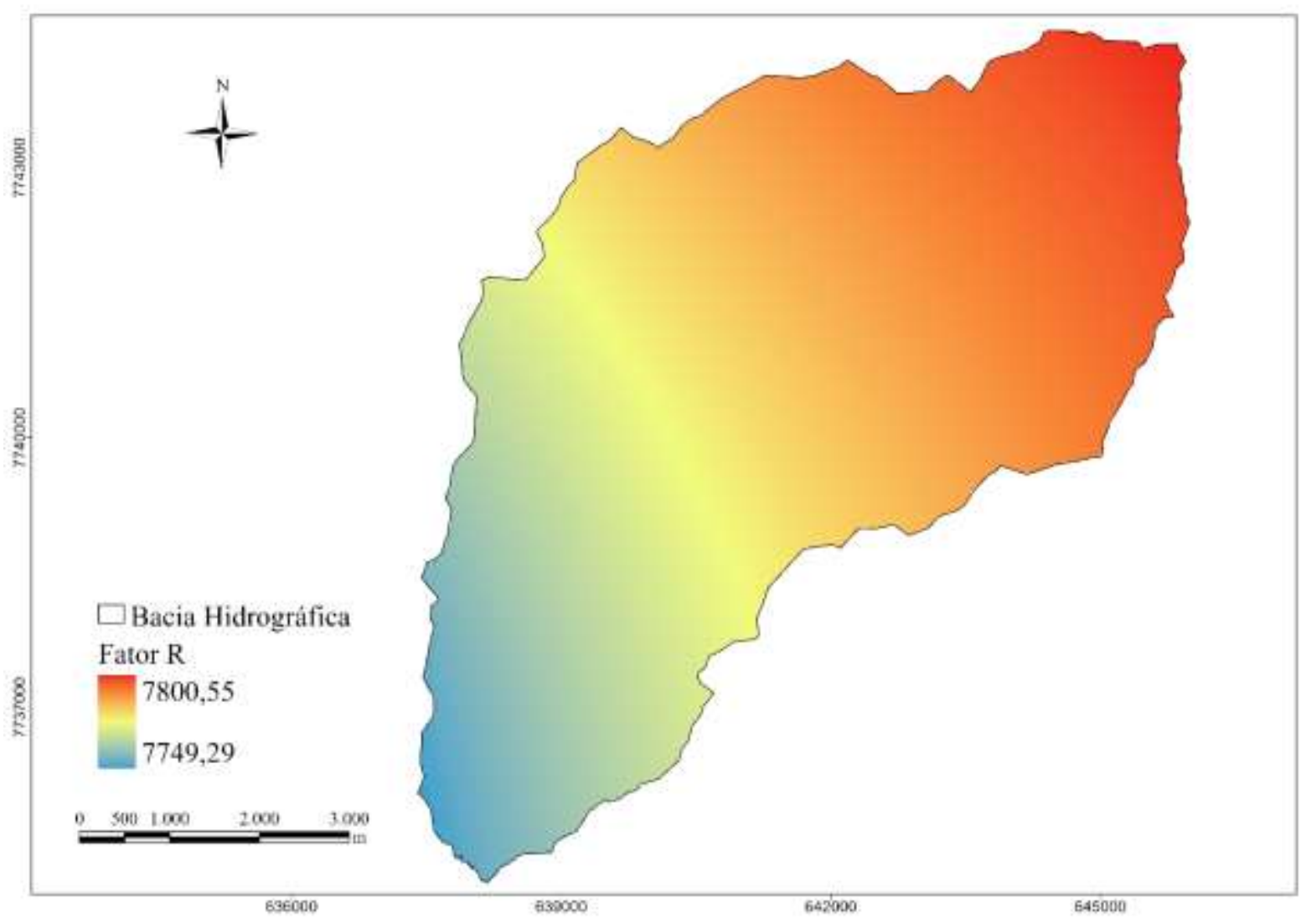

Fonte: Autores, (2020).

Arai et al. (2010) avaliaram a espacialização da erosividade na bacia hidrográfica do Rio Dourados, MS, encontraram valores entre 3355 a $4814 \mathrm{MJ} \mathrm{mm} \mathrm{ha}^{-1} \mathrm{~h}^{-1}$ ano, resultados menores de erosividade comparado a este trabalho. Galdino. (2012) na bacia do Alto Taquari encontrou resultados de $7442 \mathrm{MJ} \mathrm{mm} \mathrm{ha}^{-1} \mathrm{~h}^{-1}$ ano. Os valores deste trabalho encontram-se dentro da variação estudada por Oliveira et al. (2012), que verificaram erosividade das chuvas de Mato Grosso do Sul entre 5770 a 13601 MJ mm ha ${ }^{-1} \mathrm{~h}^{-1}$ ano e Panagos et al. (2017), encontraram resultados de erosividade acima de $<7000 \mathrm{MJ} \mathrm{mm} \mathrm{ha}^{-1} \mathrm{ano}^{-1} \mathrm{para}^{\mathrm{o}}$ Brasil.

Os valores médios mensais do $\mathrm{E}_{\mathrm{I} 30}$ variaram entre 100 a $1434 \mathrm{MJ} \mathrm{mm} \mathrm{ha}^{-1} \mathrm{~h}^{-1}$ ano (Fig. 5). Nos meses de janeiro e dezembro foram encontradas as precipitações mais elevadas, o que contribui para os maiores índices de erosividade, superiores a $1000 \mathrm{MJ} \mathrm{mm} \mathrm{ha}^{-1} \mathrm{~h}^{-1}$ ano, classificado como erosividade alta. Nos meses fevereiro, março, outubro e novembro têm-se valores de erosividade média mensal superior a $700 \mathrm{MJ} \mathrm{mm} \mathrm{ha}^{-1} \mathrm{~h}^{-1}$ ano, considerados erosividade alta. Já os meses com menores precipitações compreendidas de maio a setembro, os valores de erosividade foram classificados de muito baixo a baixo. Os resultados encontrados por Arai et al. (2010) e Trindade et al. (2016), corroboram com os deste trabalho, pois foi verificado diferenças no índice de erosividade ao longo do ano. Outros autores como Back \& Poleto. (2017); Borges et al. (2020) e França et al. (2020) também encontraram resultados semelhantes, com tendências de aumento da erosividade com aumento das chuvas.

Nos meses observados os maiores índices de erosividade (outubro a março), são os meses que podem apresentar os maiores riscos de ocorrência de perdas de solos por erosão hídrica, sendo necessário adoção de técnicas de manejo que visa minimizar os processos erosivos. 
Figura 5. Espacialização dos valores médios mensais do EI30 em MJ mm ha ${ }^{-1} \mathrm{~h}^{-1}$ ano da bacia hidrográfica Córrego Fundo, Aquidauana - MS.

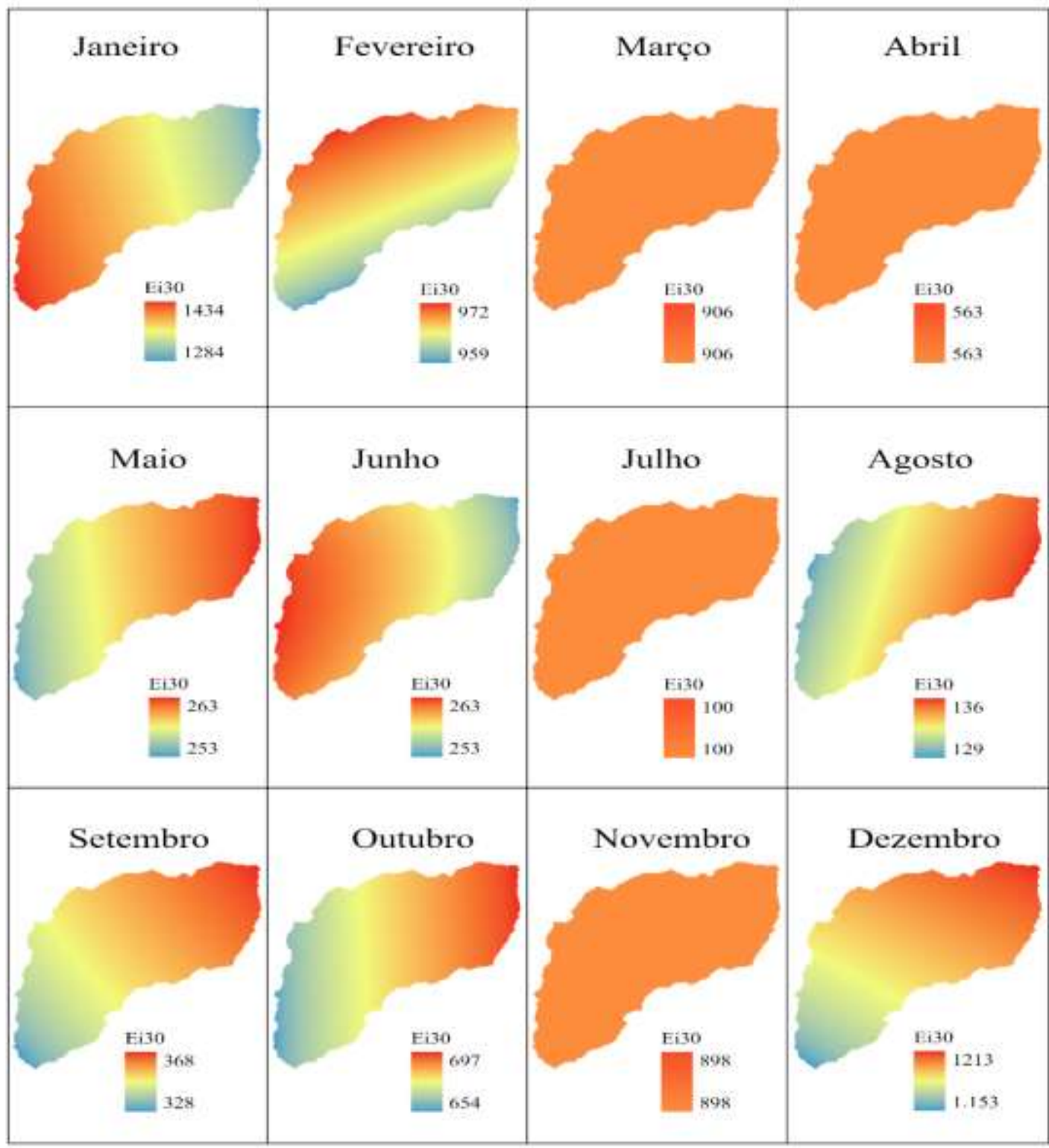

Fonte: Autores, (2020).

A erosividade mensal assemelha-se com a distribuição da precipitação ao longo do ano (Fig.6), sendo possível diferenciar os períodos secos e chuvosos e com maiores e menores índices erosivos, podendo também ser observada uma relação direta entre a precipitação e a erosividade (coeficiente de correlação $r=0,99$ ). 
Figura 6. Erosividade mensal e distribuição da precipitação ao longo dos meses.

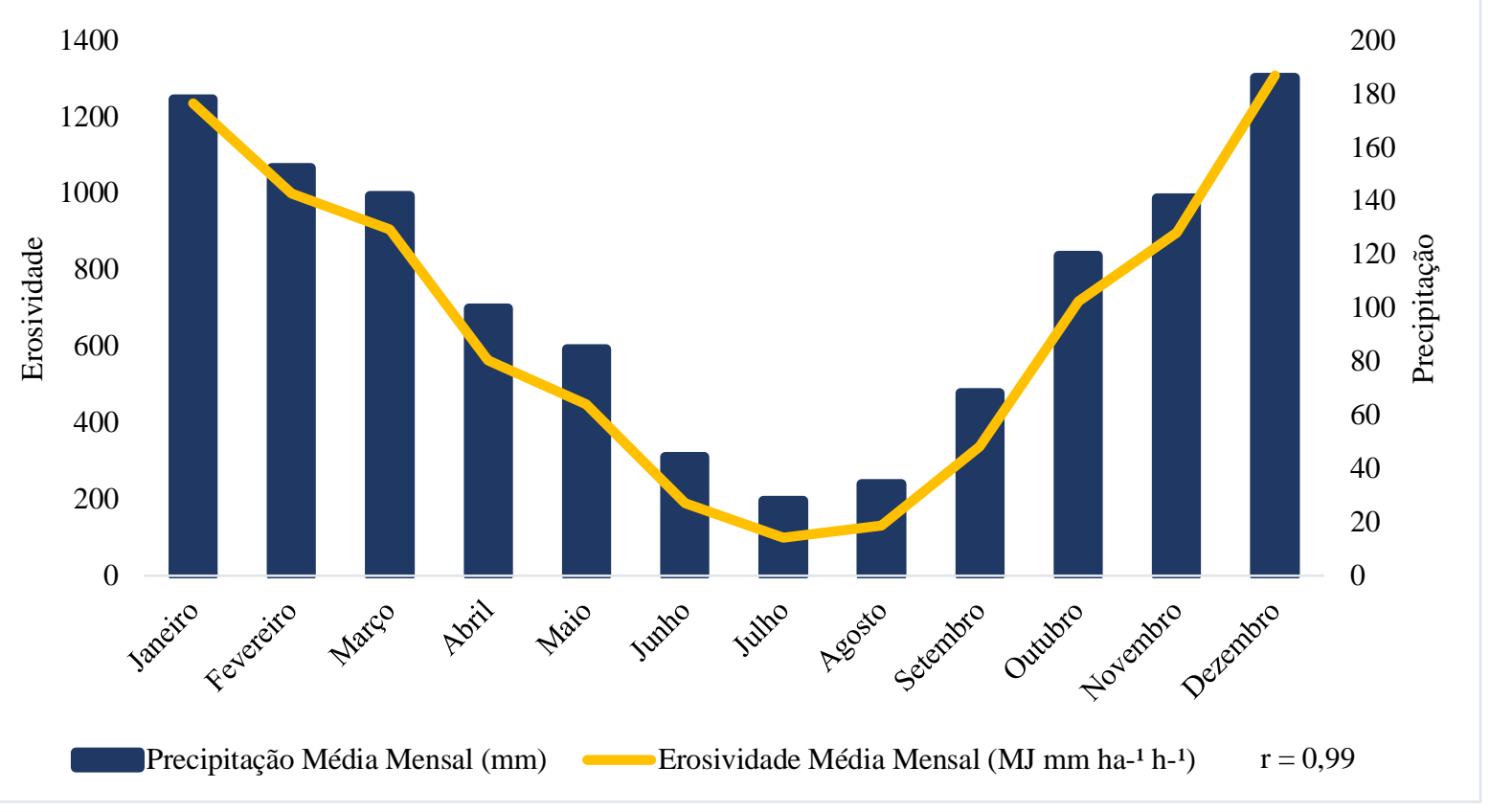

Fonte: Autores, (2020).

\section{Conclusão}

Os resultados deste trabalho apresentam informações relevante para subsidiar o planejamento de conservação do solo e da água, pois foi possível verificar ao longo do ano os meses que apresenta maiores suscetibilidade a erosão, o que permite verificar quais período são melhores para realização das práticas agropecuárias, com finalidade não apenas aumentar a produtividade, mas também de promover a conservação do solo e água de maneira mais sustentável.

A erosividade média anual variou entre 7749,29 a 7800,55 $\mathrm{MJ} \mathrm{mm} \mathrm{ha}^{-1} \mathrm{~h}^{-1}$ ano, com uma erosividade média de 7.781 MJ mm ha ${ }^{-1} \mathrm{~h}^{-1}$ ano. Os meses de maiores erosividade estão relacionados com os períodos chuvosos da região. Alguns meses do ano a erosividade mensal foi classificada muito baixo a baixo, no entanto a erosividade média anual foi considerado alta.

\section{Agradecimentos}

O presente trabalho foi realizado com apoio da Coordenação de Aperfeiçoamento de Pessoal de Nível Superior Brasil (CAPES) - Código de Financiamento 001.

\section{Referências}

ANA. Agência Nacional de Águas. Sistema de Informações Hidrológicas, HidroWeb. http://www.snirh.gov.br/hidroweb/publico/medicoes_historicas_abas.jsf.

Anjos, R. S., Candeias, A. L. B., \& Nóbrega, R. S. (2017). Mapeamento da precipitação estimada e observada no semiárido Perna mbucano e sua relação com a modelagem de dados espaciais. Revista Brasileira de Cartografia, 69(3), 447-462.

Angulo-Martínez, M., \& Beguería, S. (2009). Estimating rainfall erosivity from daily precipitation records: A comparison among methods using data from the Ebro Basin (NE Spain). Journal of Hydrology, 379(1-2), 111-121. https://doi.org/10.1016/j.jhydrol.2009.09.051

Arai, F. K., Gonçalves, G. G., Pereira, S. B., Comunello, É., Vitorino, A. C., \& Daniel, O. (2010). Espacialização da precipitação e erosividade na Bacia Hidrográfica do Rio Dourados-MS. Engenharia Agrícola, 30(5), 922-931.

ArcGIS PRO (2020). Download \& install. https://pro.arcgis.com/.

Back, Á. J., \& Poleto, C. (2017). Avaliação do potencial erosivo das chuvas de Florianópolis-SC. Revista Brasileira de Climatologia, 21. 
Bertoni, J., \& Lombardi Neto, F. Conservação do solo. 4.ed. São Paulo: Ícone Editora, 1999. 355p.

Borges, F. R. F., Ezezinos, K. E., \& Vieira, E. M. (2020). A erosividade da chuva nos municípios mineiros da bacia do rio Doce, por meio do programa computacional net Erosividade MG. Research, Society and Development, 9(11), e55791110126-e55791110126.

CEMTEC/MS - SEMAGRO. Centro de Monitoramento do Tempo e do Clima de Mato Grosso do Sul - Centro de Monitoramento do Tempo e do Clima de Mato Grosso do Sul - Secretaria de Estado de Meio Ambiente, Desenvolvimento Econômico, Produção e Agricultura Familiar. Banco de dados. http://www.cemtec.ms.gov.br/boletins-meteorologicos.

Fayas, C. M., Abeysingha, N. S., Nirmanee, K. G. S., Samaratunga, D., \& Mallawatantri, A. (2019). Soil loss estimation using rusle model to prioritize erosion control in KELANI river basin in Sri Lanka. International Soil and Water Conservation Research, 7(2), $130-137$.

França, M. V., de Medeiros, R. M., \& de Araújo, W. R. (2020). Erosividade na bacia hidrográfica do rio Ipojuca, PE-Brasil. Research, Society and Development, 9(7), e931974892-e931974892.

Galdino S (2012) Estimativa da perda de terra sob pastagens cultivadas em solos arenosos da bacia hidrográfica do alto taquari - MS / MT. tese (doutorado) — Universidade Estadual de Campinas. Faculdade de engenharia agrícola.

Mello, Y. R., Kohls, W., \& De Oliveira, T. M. N. (2017). Uso de diferentes métodos para o preenchimento de falhas em estações pluviométricas. Boletim de Geografia, 35(1), 112-121. http://dx.doi.org/10.4025/bolgeogr.v35i1.30893.

Ministério da Agricultura, Pecuária e Abastecimento (MAPA). Conservação do Solo e da Água. https://www.gov.br/agricultura/ptbr/assuntos/sustentabilidade/conservacao-do-solo-e-da-agua

Oliveira, P. T. S., Rodrigues, D. B. B., Alves Sobrinho, T., Carvalho, D.F., \& Panachuki, E. Saptial Variability of the rainfall erosive potential in the State of Mato Grosso do Sul, Brazil. Engenharia Agricola. v32, p. 69-79, 2012.

Panagos, P., Borrelli, P., Meusburger, K., Yu, B., Klik, A., Lim, K. J., \& Sadeghi, S. H. (2017). Global rainfall erosivity assessment based on high-temporal resolution rainfall records. Scientific reports, 7(1), 1-12.

Santos, C. (2008). N. El Niño, La Niña e a erosividade das chuvas no Estado do Rio Grande do Sul. Universidade Federal de Pelotas, Faculdade de Agronomia Eliseu Maciel, Programa de Pós-Graduação em Agronomia.

Silva, M. A. D., Silva, M. L. N., Curi, N., Santos, G. R. D., Marques, J. J. G. D. S., Menezes, M. D. D., \& Leite, F. P. (2010). Avaliação e espacialização da erosividade da chuva no Vale do Rio Doce, região Centro-Leste do Estado de Minas Gerais. Revista Brasileira de Ciência do Solo, 34(4), 1029-1039.

Silva, L. D., \& Bacani, V. (2017). Análise da Fragilidade Ambiental e das Áreas de Preservação Permanente da Bacia Hidrográfica do Córrego Fundo. Município de Aquidauana-MS-Caderno de Geografia, 27(49).

Trindade, A. L. F., Oliveira, P. T. S. D., Anache, J. A. A., \& Wendland, E. (2016). Variabilidade espacial da erosividade das chuvas no Brasil. Pesquisa Agropecuária Brasileira, 51(12), 1918-1928.

Wischmeier, W. H. \& Smith, D. D. Predicting rainfall erosion losses: a guide to conservation planning. Washington, United States Departament of Agriculture. Agriculture Handbook, v. 53, 1978. 